\title{
Investigation of corruption prevention plan in construction industries
}

\author{
Aditya Arie Hetami; Muhammad Fikry Aransyah* \\ Department of Business Administration, Mulawarman University, Indonesia \\ *To whom correspondence should be addressed. Email: fikryaransyah@fisip.unmul.ac.id

\begin{tabular}{|l|l|l|l|l|}
\hline DOI: & Received: & Revised: & Accepted: & Published: \\
10.22437/ppd.v8i1.8722 & 10.02 .2020 & 21.04 .2020 & 25.04 .2020 & 30.04 .2020 \\
\hline
\end{tabular}

\begin{abstract}
.
The business construction in Indonesia is subject to widespread corruption. The efficiency of business construction operations is constrained by corrupt judiciaries, which complicate the resolution process and weaken the protection of property rights. Construction industry corruption undermines the results of Indonesia's construction project and construction industry. The purpose of this paper is to provide an overview of corruption in construction activities so that stakeholders have exposure and discuss the prevention plan of corruption practices. A complete literature review identified a total of 10 preventive corruption practices in the construction industry were (1) enforcement of the law, regulation, and sanction; (2) high integrity and honest construction culture; (3) active reporting channel; (4) audit mechanism; (5) code of conduct; (6) public disclosure; (7) whistle-blowers protection; (8) Comprehensive supervision; (9) appropriate training program; and (10) income level adequacy. This paper seeks to thoroughly investigate an effective preventive plan in corruption practices, especially the construction sector. It provides insight and increases awareness of corruption practices among the construction stakeholders and society.
\end{abstract}

Keywords: Construction business, Corruption, Prevention plan

JEL Classification: D73, L78

\section{INTRODUCTION}

One thing that is hampering Indonesia's economy today is the slow pace of construction development - this is marked by the lack of quality and quantity of construction or infrastructure. Indonesia's infrastructure seems to have difficulty encouraging structural and rapid development in Global Competitiveness Report 20152016, compiled by the World Economic Forum (WEF). In WEF, Indonesia ranks 62nd out of 140 countries in terms of construction development, where this ranking showed in common work standards but instead caused several significant problems in the Indonesian economy (Indonesia Investment, 2019).

Moreover, corrupt practices in the construction industry damage the reputation of the industry. It causes investors to lose their trust in the construction industry of the country. The corruption practices create distrust towards the companies, and the corrupt practices have been generated as a culture. Thus, corruption is worsening in the construction industry (Melgar, Rossi, \& Smith, 2010). On the other hand, the high level 
of corrupt practices in a country also affects the consideration of global institutions to invest in the market of the country (Olken, 2007).

It is essential to define the preventive plan and implement the preventive plan actively and progressively in order to prevent aggravation of the corrupt practices and also reduce its consequences towards the construction industry. The preventive plan is significant because prevention is always better than curing the problems that arose. This paper seeks to thoroughly investigate corruption practices in the construction sector, which are capable of developing an effective preventive plan. It provides insight and increases awareness of corruption practices in the Indonesian construction industry among the construction stakeholders and society.

In conclusion, there are still various undiscovered effects of undertaking corruption practices in the construction industry towards the country. These consequences, which are imposed by the corrupt practices in the construction industry, ruin the healthy development of the country and should not be overlooked. Therefore, research on corruption practices in the construction industry is necessary to examine the existence of corrupt practices in order to generate an effective preventive plan to reduce corruption practice in the Indonesian construction industry.

\section{LITERATURE REVIEW}

\section{Corruption practices}

Corruption practice is a global phenomenon and commonly exercised in the business all around the world, which undermines the contribution towards the development of the country. Some researches highlighted the illegal nature of corruption and defined corruption variously. Corruption is an umbrella term that covers various wrongful acts that abuse the responsibilities for private interest. In other words, when the corruption topics are brought up, the intention and benefits of the corruption participants will be discussed simultaneously. Corruption is a fraudulent behavior regularly undertake by those with unethical intentions to obtain personal benefits through the shortcut (Cuervo-Cazurra, 2015).

Besides, the Indonesian Criminal Code defines corruption as an act against the law to enrich oneself or others, both individuals and corporations, that can harm the country's economy. There are 30 criminal acts of corruption, which are categorized into seven types, namely state financial losses, bribery, extortion, embezzlement, fraud, conflict of interest in the procurement of goods and services, and gratification.

Corruption practices ordinarily comprise two parties include the giver and recipient, at which giver requests the recipient to perform a hidden task which is within the recipient's job scope in order to acquire certain benefits. Moreover, it involves underlying economic relationships such that a person offers monetary benefits to the other party to persuade the party to assist him or her to gain certain advantages instead of upholding their position (Rose-Ackerman, 2006). The corruption practices are about inducing the official to abuse his position by offering benefits like payment and promise.

Due to the existence of different forms of corruption practices, a list of forms of corruption is summarised under Table 1. to describe each of the corruption forms with the construction activities. 
Table 1. Forms of corruption in construction industry

\begin{tabular}{|c|c|}
\hline Form of Corruption & Description \\
\hline Bid rigging & $\begin{array}{l}\text { The tenderer intentionally establishes a restricted situation (e.g., short time limit } \\
\text { and insufficient requirement) during tendering to help the preferred tenderer win } \\
\text { the tender. }\end{array}$ \\
\hline Bribery & $\begin{array}{l}\text { Payment to gain advantage or avoid disadvantage in projects. ' The payment can } \\
\text { be in cash, affirmative appointments, and special privileges. }\end{array}$ \\
\hline Collusion & $\begin{array}{l}\text { All tenders collude the overall tendering costs for significant projects, } \\
\text { intentionally raising or lowering the tendering costs to create a situation familiar } \\
\text { to high tendering costs. }\end{array}$ \\
\hline Conflict of interest & $\begin{array}{l}\text { Professionals who can not perform their roles impartially due to conflicting } \\
\text { personal or professional interest in a construction project. For example, a site } \\
\text { supervisor supervises a site on behalf of the contractor, but the site supervisor } \\
\text { has a customer relationship. }\end{array}$ \\
\hline $\begin{array}{l}\text { Dishonesty and } \\
\text { unfairness }\end{array}$ & $\begin{array}{l}\text { Untrustworthy and unequal conduct that is common in tendering, contract } \\
\text { negotiation, and building. For example, contractors generate sub-standard } \\
\text { works, overclaim project expenses, and gender bias. }\end{array}$ \\
\hline Embezzlement & $\begin{array}{l}\text { The client misappropriates the construction projects fund leading to delay } \\
\text { payment to the contractor resulting in project postponement and failure. }\end{array}$ \\
\hline Extortion & $\begin{array}{l}\text { Conduct in the form of pushing bribe extraction and demanding assistance from } \\
\text { major parties to achieve the desired outcome. Extortion occurs typically } \\
\text { between two project groups, for example, from the main contractor to the } \\
\text { subcontractor and from the client to material suppliers. It also abuses project } \\
\text { funds that include supplying other citizens with illegal income. }\end{array}$ \\
\hline Fraud & $\begin{array}{l}\text { A common type of corruption involving document alteration and deliberately } \\
\text { misguiding and concealing documents, theft of equipment, and materials, } \\
\text { producing fake invoices for materials not obtained on-site. }\end{array}$ \\
\hline Front companies & $\begin{array}{l}\text { The organizational entities created by the senior client or government } \\
\text { organization staff to gain unlawful benefits in the rewarding construction } \\
\text { contract. }\end{array}$ \\
\hline Kickback & $\begin{array}{l}\text { The tenderer offers the client's consultant economic advantages in return for } \\
\text { favored outcomes, such as tendering and extending the tendering period. }\end{array}$ \\
\hline Negligence & $\begin{array}{l}\text { A practitioner who cannot exercise honesty and ethical behavior. Negligence } \\
\text { practices include insufficient design due to poor material quality, craft, and } \\
\text { supervision. }\end{array}$ \\
\hline Nepotism & $\begin{array}{l}\text { Apply to actions in which a tenderer can secure a construction tender due to an } \\
\text { organization staff's assistance that may consist of unique relationships like a } \\
\text { family relationship. This corruption activity undoubtedly decreases project } \\
\text { efficiency if the awarded tenderer is not eligible. }\end{array}$ \\
\hline
\end{tabular}

Source: Vee \& Skitmore, 2003; Alutu, 2007; De Jong, Henry, \& Stansbury, 2009; Hartley, 2009; Bowen, Edwards \& Cattell, 2012; Edwards \& Cattell, 2012; and Le, Shan, Chan \& Hu., 2014b

\section{METHODS}

The literature review includes secondary research data. In this research, the definition of corruption in connection with prevention construction activities will be discussed in order to provide readers with a better understanding of corruption in the construction industry. The literature review takes place in order to provide a comprehensive overview of the research topic based on local and international corruption issues in the construction sector. In order to contain corruption activities and 
to reduce the number of unethical actions in the construction industry, the impacts of corruption practices and future prevention measures will be analyzed and addressed.

\section{RESULTS AND DISCUSSION}

\section{Enforcement of law, regulation, and sanction}

Corruption practice is a crime and generally committed under the table, causing difficulties in discovering such practice. In such circumstances, the law enforcement and regulation are crucial to combat corruption in the construction. Law and regulation, especially regarding the corruption practices, should be comprehensively enforced in the construction industry to reduce the corruption rate (Gunduz \& Önder, 2013; Kenny, 2009; Sohail \& Cavill, 2006; Zou, 2006; Nordin, Takim \& Nawawi, 2012; Le Shan, Chan, \& Hu, 2014a). However, the existing corruption-related laws and regulations should also be improved to reinforce the anti-corruption precautions strictly within the construction industry.

The research study of Zou (2006) regarding the preventive corruption plan in China received a respond from interviewee which claimed that besides strengthening the management of construction organizations, the laws, and regulations, as well as sanctions in the construction industry, is a must to prevent vulnerability to the unscrupulous practitioners to practice corruption acts. The establishment of strict sanctions can increase the fear of corruptors, which eventually reduces corruption practices (Tabish \& Jha, 2012). However, construction regulations like rules in contractor selection, dispute resolution, and implementation of construction must be established (Sohail \& Cavill, 2006). Inadequate publication of amended regulation creates vulnerabilities to unethical practitioners as it fails to gain the attention of construction stakeholders towards the amendments (Nordin, Takim \& Nawawi, 2011). Not only developing corruption-related laws and regulations, the existing laws and regulations should also be reviewed strictly in combating the corrupt practices in the construction industry. On the other hand, Nordin, Takim, \& Nawawi (2012) emphasized that it is crucial to ensure that the development and maintenance of the corrupted-related laws and regulations are unambiguous and understandable (Yee, 2019).

The laws and regulations to deal with the corruption practices should be implemented fairly and strictly to all the construction practitioners (Kenny, 2009) regardless of the position or status of the practitioners in the construction industry (Nordin, Takim \& Nawawi, 2012). It is critical to make sure that there is no personnel escape from the sanction of the corrupt acts by paying a bribe. It is essential to ensure that the laws and regulations are established and implemented at the same time in the construction industry to eliminate corruption practices (Zou, 2006). Other than that, the existing sanction towards the unscrupulous construction practitioner should be review in order to increase the fear of immoral construction practitioners to participate in the corruption activities and reduce the potential in committing unethical behaviors in the construction projects. Zou (2006), Sohail \& Cavill (2008), Nordin, Takim, \& Nawawi (2012) \& Le, Shan, Chan, \& Hu. (2014a) mentioned that the corruption cases in the construction projects should be investigated strictly to discover the corruptors, and such corruptors must be punished severely and according to their acts. It can reduce the corrupt practices in the construction projects as individuals tend to learn from experience and correct their wrongdoing after the punishment.

In order to understand the core of the corruption prevention plan, it is significant for existing laws and regulations relating to corruption strengthened to reinforce anti- 
corruption measures exclusively within the construction industry. In addition to creating laws and regulations related to corruption, existing laws and regulations should also be strictly checked to combat corrupt practices in the construction industry. It is also essential to ensure that there is no personal exemption from punishing illegal acts by paying the bribe. Other than that, the current sanctions against the unscrupulous construction practitioner should be checked to increase the apprehension of dishonest construction practitioners to engage in corruption activities and reduce the potential for unethical behavior in construction projects. It can eliminate corrupt practices in construction projects as individuals tend to learn from experience and right after the punishment.

\section{Effective reporting channel}

One of the most effective ways to contain the increasing number of corruption cases is through a practical and protected reporting channel (Yee, 2019). The corruption acts in the construction projects cannot be uncovered quickly by law enforcement units, especially when the evidence of the corruption acts is unavailable most of the time because such acts are always able to be concealed (Bowen, Edwards, \& Cattell, 2012). Therefore, the reporting channel is vital as it provides a platform for people to report the cases immediately to the law enforcement units when they realized the corrupt acts happen.

The whistle-blowing hotline should be provided effectively and formally in order to allow the corruption practices to be discovered (Bowen, Edwards, \& Cattell, 2012; Gunduz \& Önder, 2013). The whistle-blowing hotline should act as a formal channel that permits the public to contact the law enforcement units once they discover the corrupt practices in the construction projects. A protected whistleblowing hotline encourages the public to report incidents of corruption (Gunduz \& Önder, 2013). In most cases, the main factor which causes the whistle-blowers to give up on reporting the corrupt acts in the construction projects is that they are unable to find a correct platform to report the corrupt acts. Therefore, it is urged that the anti-corruption community create an active whistle-blowing hotline in the Indonesian construction industry to the public in order to uncover more of the corruption activities in the construction projects.

However, active reporting channel is also one of the critical preventive plans to corruption practices. The active and efficient reporting systems, such as an independent hotline for corruption, should be adopted and implemented in order to unearth the hidden corruption practices (Owusu, Chan, Degraft, Ameyaw, \& Robert, 2019). The development of a well-structured whistle-blowing mechanism act as a deterrent to corruption practices as it encourages ones to report the identified and probed corrupt cases without fear (Oladinrin, Ho, \& Lin, 2016) and without exposing identity. The establishment of a healthy whistle-blower plan which protects the whistle-blowers is also vital to stimulate ones' encouragement to disclose the corruption acts (Sohail \& Cavill,2008).

Therefore, a corruption prevention plan can start from creating a forum for people to report crimes to law enforcement agencies immediately when they know the illegal actions happen. An active monitoring platform, however, is also a vital prevention mechanism for corruption activities. Developing a well-structured whistle-blowing system serves as a deterrent to unethical activities because it allows people to expose corrupt cases without apprehension and without revealing identity. Setting up a healthy whistle-blower plan to protect whistle-blowers is also essential to promote the motivation of those to report corruption actions. In most cases, the critical thing that 
causes whistle-blowers to give up exposing corrupt actions in construction projects is that they can not find the right forum to expose corrupt actions. Therefore, it is urged that the anti-corruption movement establish an active whistle-blowing hotline for the public in the Indonesian construction industry to expose more corruption activities in construction projects.

\section{High integrity and honest culture}

An honest culture in the construction industry helps to promote and develop positive values, high level of moral and ethical standards among the construction practitioners. The construction projects are made up of different concurrent activities and involve a variety of parties; it causes difficulties in supervising every construction activity. Therefore, the development of honest and anti-corruption culture is an essential key to ensure that the corrupt practices are kept in a minimum amount in the construction industry. The establishment of ethical construction culture in the construction industry can minimize corrupt practices effectively in the construction industry (Zou, 2006).

Not merely the construction companies, the government also plays a significant role in promoting ethical and high integrity construction culture in conducting the construction projects all the time (Nordin, Takim \& Nawawi, 2012; Zou, 2006). The government should prevent creating a culture like corruption will not be unearthed quickly. Furthermore, in order to create an honest and ethical culture in the construction industry, several approaches like recruiting competent leaders, staff training, increasing awareness, and developing trustworthy reporting channels can be considered.

Furthermore, the construction practitioners themselves are the vital key to develop and promote an honest and clean culture within the construction industry. Controls on the employee selection must be significantly applied in the construction industry in order to filter out the unscrupulous individuals to reduce corrupt acts in the construction projects. Gunduz \& Önder (2013) proposed that before the employment of the construction practitioners in the construction companies, several verification and checks should be conducted. For instance, past employment, education, and certification should be examined and verified strictly to inspect whether there is past involvement in the corrupt practices of the recruiters. Besides that, the ethical behaviors of the construction practitioners should be rewarded at the right time in order to build a positive construction industry culture (Yee, 2019).

Therefore, a corruption prevention plan can start from high integrity and honest culture. It is proven that this culture in the construction industry helps foster and grow positive values, high moral and ethical standards among building practitioners. Building projects consist of numerous overlapping tasks and include many parties; it creates difficulties in managing any building operation. Therefore, cultivating an ethical and anti-corruption culture is key to ensuring that unethical practices are held to a minimum in the construction industry. The government should not easily dismantle a society like corruption. Therefore, to build an honest and ethical culture in the construction industry, many strategies can be considered, such as hiring competent leaders, training staff, raising awareness, and creating trustworthy reporting channels.

\section{Audit mechanism}

An audit can be defined as a mechanism to examine the financial report of a company by an independent external organization. The construction audit is to inspect various aspects of the projects in order to ensure the projects are performing accordingly 
and align with the agreed contract. The audit mechanism in the construction industry stands a crucial role in managing construction projects. In order to reduce the corruption rate in the construction industry, strict audit mechanisms should be developed in construction projects to control the processes (Gunduz \& Önder, 2013; Le, Shan, Chan, \& Hu, 2014a; Zou, 2006; Le, Shan, Chan, \& Hu, 2014b; Sichombo, Muya, Shakantu \& Kaliba, 2009).

Moreover, the audit mechanism is a crucial preventive strategy for corruption practices (Yee, 2019). The corruption crime is not apparent due to its distinctive character with the other criminal cases such as lack of crime scene, left-over impression, and fingerprints and the involving parties are often found unwilling to reveal the truth. Therefore, it is often unable to be revealed and followed up (Owusu, Chan, Degraft, Ameyaw, \& Robert, 2019). In order to discover the hidden corruption acts in construction activities, adequate probing measures, and investigation have to be implemented (Man-wai, 2006). Comprehensive technical auditing on a construction project must be performed to audit the construction projects documents, work done and technical specification (Sichombo, Muya, Shakantu \& Kaliba, 2009; Zou, 2006) as well as contractual details like contract variations (Shen \& Song, 1998; Sohail \& Cavill, 2006). The auditors should become familiar with adequate auditing mechanisms in order to successfully uncover corruption risk and conduct (Man-wai, 2006). It is due to one who does not understand the construction process to discover illegal activities due to the complex nature of construction (Sichombo, Muya, Shakantu \& Kaliba, 2009).

Sichombo, Muya, Shakantu \& Kaliba, (2009) mentioned that the adoption of technical auditing should be committed in the pre-contract and post-contract stage, and it helps to lower the construction cost by minimizing and overcoming the corrupt practices in the construction projects. Meanwhile, the post-contract audits can evaluate the difference between the contract requirements and physical works. Zou (2006) also stated that the audit mechanism is necessary for the construction projects and should be carried out on the final account of the construction project to ensure that the works are done according to a quality standard, and the claiming are based on the work done at the site.

Nevertheless, Gunduz \& Önder (2013) proposed two types of technical audit mechanisms to the construction projects, which include internal and external audits. However, the adoption of internal audits in the Turkish construction industry is a more popular method to prevent corruption compared to the external audit. The internal audit focuses more on the issues regarding the construction project practices and processes in order to manage the relevant risks. However, the external audit focus on the examination of the financial accounts of the construction projects to determine if the records are reflecting the actual works.

Therefore, the corruption prevention plan reviews various aspects of the projects to ensure that the projects work correctly and comply with the negotiated contract. The construction audit process plays a crucial function in handling building projects. Effective monitoring and investigation can expose the secret actions of wrongdoing in construction operations. Comprehensive technical auditing of building project records work completed, and technical requirements and contractual information such as contract variations must be conducted must and be enforced.

Auditors are the leading player in corruption prevention plans in order to execute 
internal and external audits. They should become familiar with appropriate auditing processes to identify corruption risk and conduct effectively. The implementation of technical auditing should be undertaken in the pre-contract and post-contract phases, helping to minimize construction costs by reducing and eliminating unethical practices in construction projects. Post-contract evaluations, meanwhile, will determine the disparity between contract conditions and physical operations. The internal audit focuses more on building project activities and procedures problems to handle the related risks. However, the external audit focuses on reviewing the building projects' financial statements to decide whether the documents represent real operations.

\section{Code of conduct}

Several research papers emphasize the importance of code of conduct as the code of conduct can enhance the professionalism, responsibility, and integrity of the construction practitioners. Furthermore, Ministry of Public Works and Public Housing (PUPR) has formulated and implemented the code of conduct with the primary objectives to describe the standard practices to be adopted in order to ensure that the construction practitioners are performing their tasks efficiently, accountably and transparently. However, the importance of code of conduct is often being neglected, and some practitioners have zero knowledge about the code of conduct when entering the construction industry.

The adequate code of conduct should be strictly established and enforced among the construction practitioners to minimize the corruption practices (Le, Shan, Chan, \& Hu, 2014a; Gunduz \& Önder, 2013; Le, Shan, Chan, \& Hu, 2014b; Kenny, 2009). Nordin, Takim, \& Nawawi (2012) stated that there is a need to obtain an adequate monitoring system and raise the integrity among the construction practitioners by assuring that the practitioners understand their core values. Sohail \& Cavill (2006) also mentioned that the code of business and professional, ethical conduct are significant preventive corruption measures as the code often contains the principles of the ethical behaviors (fairness, integrity, and accountability) of a business and professional in executing their tasks. For instance, the International Federation of Consulting Engineers (FIDIC) develop the code of ethics of engineers, which is a significant preventive measure of corruption in the construction industry. One of the criteria of an engineer in the code of ethics includes that the engineer should not offer and accept any remuneration as it influences the decision-making process in the construction projects.

The code of conduct is perceived as an essential preventive strategy towards corruption practices in the Malaysian construction industry (Yee, 2019). The code of conduct is one of the useful tools to tackle corruption practices in the construction industry. Hosseini et al. (2019) recommended that the construction organizations including developers, consultants, and contractors to establish a framework to implement and access the code of ethics in order to prevent the corrupt practices in construction projects. Enforcement of code of conduct, which used to specify the standards of conduct for business and professionals, can substantially reduce the number of corruption acts (Sohail \& Cavill, 2008). It is an important key to prevent corruption. Sohail \& Cavill (2008) further claimed that in order to strengthen the professional institution, the professionals in the construction industry should have adequate training in codes of conduct to the construction stakeholders.

The code of conduct provides the guidance of the ethical principle of the 
professionals to discipline the construction practitioners and to ensure that there are high integrity and accountability among the professionals. Besides, the code of conduct not merely to outline the best ethical standards, it also helps to develop anti-corruption procedures to the construction industry. Therefore, the code of conduct should not be neglected but to be enforced strictly in the construction industry to eliminate corruption practices.

\section{Public disclosure}

Public disclosure can also be known as a transparency mechanism at which it involves disclosing daily works to the public to obtain public notice. It is to make the whole construction process to be opened and to allow the public to notice every decision made within the construction projects. The open and transparent construction process should be established especially in deciding on the construction projects include tendering and developing construction law (De Jong, Henry, \& Stansbury, 2009; Gunduz \& Önder, 2013; Sohail \& Cavill, 2006; Le, Shan, Chan, \& Hu, 2014b; Kenny, 2009; Nordin, Takim \& Nawawi, 2012; Zou, 2006; Le, Shan, Chan, \& Hu, 2014a).

Besides, in order to prohibit corruption practices in construction, the amount of information regarding construction projects like budgets of projects, public accounts, contractual arrangements, and annual reports should be disclosed more to the public (Sohail \& Cavill, 2008). Moreover, the ordinary publication of construction contracts to the public can improve the governance of construction projects and indirectly overcome the impacts of corruption in the construction industry (Kenny, 2012). Kenny (2009) also recommended that the freedom in terms of accessibility of construction projects information has to be increased, and the construction industry should undergo fiscal reform for transparency to monitor the construction projects publicly.

A high level of public disclosure of construction information can allow the corrupt practices in the construction projects to be detected efficiently. Thus, the establishment of open construction processes should be adapted from procurement to completion stage in construction projects, and the transparent public processes should be adopted by all parties who involve in the construction projects in order to reduce corrupt practices in the construction projects (De Jong, Henry, \& Stansbury, 2009).

Public disclosure in corruption prevention plan is to allow the public to note any decision taken within the construction projects. in order to prevent unethical practices in construction, more information on building projects such as project budgets, financial accounts, contractual contracts, and annual reports should be reported. High public disclosure of construction details will effectively identify unethical practices in building projects. Therefore, the establishment of open construction processes should be adapted from procurement to completion in construction projects, and all parties involved in construction projects should follow transparent public processes.

\section{Whistle-blowers protection}

Though whistle-blowing hotline allows the public to report the corrupt practices in the construction projects, it puts the whistle-blowers in danger and risk. As in research of Ameyaw et al. (2017), it founded that the whistle-blowers are not appropriately protected and having the risk of being exposed. However, Bowen, Edwards, \& Cattell (2012) in their research received respond which expressed that it is difficult in reporting the incidents of corruption as the whistle-blowers will be 
threatened when the identity is exposed. Not only threatened by the corruptors, but the whistle-blowers are also disdained by other construction stakeholders on reporting corrupt acts, although they make a moral judgment.

Therefore, not only active whistle-blowing hotline but protection towards the whistle-blowers is also critical (Gunduz \& Önder, 2013; Ameyaw et al., 2017; Bowen, Edwards \& Cattell, 2012). All the identity of the whistle-blowers who report the incidents of corruption is required to keep low and maintain secrecy. It is to protect the whistle-blowers from any threatening risk.

The whistleblower will become black sheep if any corruption practices. They must free from any threat in order to give full information regarding corruption practices. The protection towards the whistle-blowers eventually helps to reduce the corrupt practices in the construction projects.

\section{Comprehensive Supervision}

Supervision of construction projects can effectively mitigate the corrupt practices in the construction industry (Zou, 2006; Olusegun, Benson, Esther, \& Michael, 2011; Le, Shan, Chan, \& Hu, 2014a). However, Zou (2006) suggested that supervision should be adopted internally and externally. For instance, internal supervision should be carried out to monitor individually on each section of the construction project process. In contrast, the external supervision should be implemented as in supervisory organization.

The research paper of Zou (2006) in the China construction industry is significantly emphasized on the comprehensive supervision works in the construction projects that can deal with the corruption practices. The research paper highlighted that it is a need to establish a complete supervising procedure, system, and organization, and the supervising officials have to be proactively and impartially in supervising the works to discover corrupt practices in the construction projects. Not merely the contractors' work at the site, the relevant consultants in the construction projects should also be closely monitored to explore the unethical act of the professional (Olusegun, Benson, Esther, \& Michael, 2011).

Furthermore, the supervision works should be carried out randomly and regularly to increase the risk of detection of malpractices. Comprehensive supervision should be one of prevention plan that it is a need to establish in order to complete supervising official, procedure, system, and organization.

\section{Adequate training system}

Good leadership is critical to bring the project success (Bowen, Edwards \& Cattell, 2012) as the leader is often responsible for controlling the overall construction process and monitoring the workers. The behaviors of the leader can affect the culture and perception towards corruption in the construction industry. Thus, Nordin, Takim, \& Nawawi (2012) stated that it is essential to ensure that the leader of the construction projects possesses a high level of integrity, ethical leadership, and competent to guide and monitor the workers instead of showing and encouraging the unethical behaviors to the other construction practitioners.

Other than the enforcement of code of conduct to the construction practitioners, Zou (2006), Sohail \& Cavill (2008) and Le, Shan, Chan, \& Hu, (2014a) also emphasized that the ethical training programs should be strengthened and provided to the construction practitioners as it is crucial to eliminate the corruption practices. 
However, construction practitioners should be appropriately trained and adequately through courses and talks by instilling the significance of professionalism and integrity in the construction industry (Nordin, Takim, \& Nawawi, 2012). Furthermore, the construction companies, including the consultants and contractors, should provide internal training to the workers to ensure that the intention to participate in corruption is eliminated (Gunduz \& Önder, 2013).

The top management of the construction projects should be well educated to assure that the leader is performing a task without corrupt acts. It is also to prevent the passing down of corruption behaviors and wrong perception towards the corruption to the bottom management in the construction industry. The internal training should emphasize and raise corruption awareness, ethical procedures, consequences of corruption, and the importance of self-regulation to the workers.

\section{Income level adequacy}

Most of the time, when the corruptors realize that the benefits of corruption override the cost of carrying out such practices, they will decide to undertake such practices to obtain immediate extra income. Therefore, it is a must to reduce such benefits and increase the cost of corruption by imposing a higher risk of being discovered and harsh punishment. However, the wages level of the construction practitioners should be reviewed (Olusegun, Benson, Esther, \& Michael, 2011; Sohail \& Cavill, 2006) in order to overcome the financial pressure and to ensure that the construction practitioners will not take it as an excuse to commit the corrupt acts in the construction projects.

Olusegun, Benson, Esther, \& Michael (2011) highlighted that the government of Nigeria should look into, review, and provide appropriate income to the construction practitioners to ensure that such income levels are adequate for the construction practitioners to live conveniently. The government can obtain adequate income levels of the construction practitioners by inspecting and researching the level of salaries and incomes that the other countries approved for their construction practitioners in the construction industry.

The primary purpose of providing the appropriate and adequate income level to the construction practitioners is to reduce the excessive greed towards money. The government can also create regulation for ease of financial pressure that the construction practitioners commonly faced and indirectly to overcome the intention of participating in corruption in the construction industry.

\section{CONCLUSIONS AND RECOMMENDATIONS}

\section{Conclusions}

Corruption practices create various adverse effects on the country. This situation is getting worse when the corruption practices exist in the construction industry as the industry act as a significant contributor to the economic and social development of the country. Thus, a clear understanding of current essential preventive strategies to corruption practices. The preventive plan was explored in the research were (1) enforcement of the law, regulation, and sanction; (2) high integrity and honest construction culture; (3) active reporting channel; (4) audit mechanism; (5) code of conduct; (6) public disclosure; (7) whistle-blowers protection; (8) comprehensive 
supervision; (9) appropriate training program; and (10) income level adequacy. Among the entire preventive plan studied above, audit mechanisms, code of conduct, and public disclosure were considered as the most effective plan by experts to prevent corruption in construction projects because these plans had connections with the causes of corruption as compared to another plan.

\section{Recommendations}

In order to reflect the real situation of corrupt practices in the Indonesian construction industry, the mixed-methods research design should be employed to incorporate the qualitative research method with the quantitative method in future studies. Due to the sensitive nature of the research area, it is helpful to undergo qualitative research to justify if the data obtained from the questionnaire survey are reliable. Furthermore, an in-depth case study will be beneficial to comprehend the nature of corrupt practices in the construction industry and provide new insights into the research area. It can help to provide triangulation (e.g., case study, interview findings, and questionnaire responses) to improve the validity and reliability of the study.

However, more researches concerning corruption are recommended in the construction industry. It is to ensure that the studies on corruption practices are carried out thoroughly. It would be interesting to extend this research to investigate the frequency of occurrence of different types of corrupt practices in the construction industry. It is also suggested that future research identifies new vulnerabilities that exist in the construction industry, which stimulates corruption. Besides, future research about the barriers hindering the implementation of anti-corruption practices in the Indonesian construction industry is recommended.

\section{REFERENCES}

Alutu, O.E. (2007). Unethical practices in the Nigerian construction industry: prospective engineers' viewpoint. Journal of Professional Issues in Engineering Education and Practice, 133(2), 84-88.

Ameyaw, E.E., Pam, E., Chan, A.P.C., Owusu-Manu, D.G., Edwards, D.J., \& Darko, A. (2017). Corrupt practices in the construction industry: A survey of Ghanaian experience. Journal of Management in Engineering, 33(6), 1-11.

Bowen, P.A., Edwards, P.J., \& Cattell, K. (2012). Corruption in the South African construction industry: A thematic analysis of verbatim comments from survey participants. Construction Management and Economics, 30(10), 885-901.

Cuervo-Cazurra, A. (2015). Corruption in international business. Journal of World Business, 51(1), 35-49.

Gunduz, M., \& Önder, O. (2013). Corruption and internal fraud in the Turkish construction industry. Science and Engineering Ethics, 19(2), 505-528.

Hosseini, M.R., Martek, I., Banihashemi, S., Chan, A.P.C., Darko, A. \& Tahmasebi, M. (2019). Distinguishing characteristics of corruption risks in Iranian construction projects: A weighted correlation network analysis. Science and Engineering Ethics, 19, 1-27.

De Jong, M., Henry, W.P. \& Stansbury, N. (2009). Eliminating corruption in our engineering/construction industry. Leadership and Management in Engineering, 9(3), 105-111.

Hartley, R. (2009). Fighting corruption in the Australian construction industry: The 
national code of practice. Leadership and Management in Engineering, 9(3), 131135.

Indonesia Investment (2019). Infrastruktur di Indonesia, Retrieved from https://www.indonesia-investments.com/id/bisnis/risiko/infrastruktur/item-381

Kenny, C. (2009). Transport construction, corruption, and developing countries. Transport Reviews, 29(1), 21-41.

Kenny, C. (2012). Publishing construction contracts to improve efficiency and governance. Proceedings of the Institution of Civil Engineers, 165(5), 18-22.

Le, Y., Shan, M., Chan, A.P.C. \& Hu, Y. (2014a). Investigating the causal relationships between causes of and vulnerabilities to corruption in the Chinese public construction sector. Journal of Construction Engineering and Management, 140(9), 1-12.

Le, Y., Shan, M., Chan, A.P.C. \& Hu, Y. (2014b). Overview of corruption research in construction. Journal of Management in Engineering, 30(4), 1-7.

Man-wai, T.K. (2006). Formulating an effective anti-corruption strategy - The experience of Hong Kong ICAC. Resource Material Series, 69, 196-201.

Melgar, N., Rossi, M., \& Smith, T.W. (2010). The perception of corruption. International Journal of Public Opinion Research, 22(1), 120-131.

Nordin, R.M., Takim, R. \& Nawawi, A.H. (2011). Critical factors are contributing to corruption in construction industry. In: 2011 IEEE Symposium on Business, Engineering and Industrial Applications (ISBEIA). 330-333.

Nordin, R.M., Takim, R. \& Nawawi, A.H. (2012). Transparency Initiatives (TI) in construction: The social psychology of human behaviours. Procedia Social and Behavioral Sciences, 50, 350-360.

Oladinrin, O.T., Ho, C.M.F. \& Lin, X. (2016). Critical analysis of whistleblowing in construction organizations: Findings from Hong Kong. Journal of Legal Affairs and Dispute Resolution in Engineering and Construction, 9(2), 1-8.

Olken, B.A. (2007). Monitoring corruption: Evidence from a field experiment in Indonesia. Journal of Political Economy, 115(2), 200-249.

Olusegun, A.E., Benson, A., Esther, I. \& Michael, A.O. (2011). Corruption in the construction industry of Nigeria: Causes and solutions. Journal of Emerging Trends in Economics and Management Science, 2(3), 156-159.

Owusu, E.K., Chan, A.P.C., Degraft, O., Ameyaw, E.E. \& Robert, O. (2019). Contemporary review of anti-corruption measures in construction project management. Project Management Journal, 50(1), 40-56.

Rose-Ackerman, S. (2006). International handbook on the economics of corruption. Cheltenham: Edward Elgar Publishing Ltd.

Shen, L., \& Song, W. (1998). Competitive tendering practice in Chinese construction. Journal of Construction Engineering and Management, 124(2), 155-161.

Sichombo, B., Muya, M., Shakantu, W., \& Kaliba, C. (2009). The need for technical auditing in the Zambian construction industry. International Journal of Project Management, 27(8), 821-832.

Sohail, M., \& Cavill, S. (2006). Corruption in construction projects. In: Proceedings of the CIB W107 Construction in Developing Countries Symposium 'Construction in Developing Economies: New Issues and Challenges'.

Sohail, M., \& Cavill, S. (2008). Accountability to prevent corruption in construction 
projects. Journal of Construction Engineering and Management, 134(9), 729738.

Tabish, S.Z.S., \& Jha, K.N. (2012). The impact of anti-corruption strategies on corruption free performance in public construction projects. Construction Management and Economics, 30(1), 21-35.

Vee, C., \& Skitmore, M. (2003). Professional ethics in the construction industry. Engineering, Construction and Architectural Management, 10(2), 117-127.

Yee, Lee Kai. (2019). Corruption Practices In The Malaysian Construction Industry: Analysing Causes And Preventive Strategies. Project Report, UTAR.

Zou, P.X.W. (2006). Strategies for minimizing corruption in the construction industry in China. Journal of Construction in Developing Countries, 11(2), 15-29. 